\title{
A DEMOCRATIZAÇÃO DA FAMÍLIA: SUBSTITUIÇÃO DA HIERARQUIA FAMILIAR PELA PARIDADE NAS RELAÇÕES CONJUGAIS E SUAS IMPLICAÇÕES PARA A FAMÍLIA BRASILEIRA CONTEMPORÂNEA
}

\section{THE DEMOCRATIZATION OF THE FAMILY: SUBSTITUTION OF THE FAMILIAR HIERARCHY BY THE PARITY IN THE CONJUGAL RELATIONS AND ITS IMPLICATIONS FOR THE BRAZILIAN CONTEMPORARY FAMILY}

\author{
SuZANa GonçALVES Lima E SILVA \\ Graduação em Licenciatura em Teologia. Graduação em andamento na Faculdade de Direito do IMES \\ suzanalima1702@gmail.com
}

ROSANGELA APARECIDA SILVA

Mestre em Direito - UNESP - Campus Franca-SP.Docente da Universidade Federal de Alfenas - UNIFAL-MG vinculada no ICHL. Professora de Propriedade Intelectual. Coordenadora e professora da Faculdade de Direito do IMES-FUMESC.

Advogada.

prof.rosangelaasilva@ig.com.br

\section{RESUMO}

A democratização da família brasileira, sobretudo no que diz respeito à paridade nas relações conjugais, está sustentada na isonomia consagrada na Constituição Federal de 1988. O problema que se discute não é a extinção da família patriarcal, mas, por que esta configuração familiar não é hegemônica na contemporaneidade. Fatores como a revolução industrial, o movimento feminista e a questão da sexualidade feminina cooperaram para o afastamento da concepção hierárquica e matrimonial da família. Assim, o objetivo do presente artigo é demonstrar ao leitor que o Direito das Famílias requer um estudo abrangente, não somente no seu aspecto jurídico como também deve ser analisado à luz de outras disciplinas. A pesquisa realizada é bibliográfica e teórica, com levantamento documental e o método utilizado é o dedutivo, com análise de obras relacionadas ao tema.

Palavras-chave: $\quad$ Constituição $\quad$ Federal; Democratização; Família; Igualdade; Patriarcalismo.

\begin{abstract}
The democratization of the Brazilian family, especially regarding about the parity in the conjugal relations, is supported in the isonomy established in the 1988 Federal Constitution. The problem that has been discussed is not the extinction of the patriarchal family, but the reason this family configuration is not hegemonic nowadays. Factors as the industrial revolution, the feminist movement and the question of female sexuality cooperated in distancing the hierarchical and marriage conception from the family. So, the objective of this article is to demonstrate to the reader that the Right of the Families demands a far-reaching study, not only in its legal aspect but it also must be analyzed under the light of other disciplines. The performed research was bibliographical and theoretical, with documentary review and deductive method, with analysis of works related to the subject.
\end{abstract}

Key words: Federal constitution; Democratization; Family; Equality; Patriarchalism. 


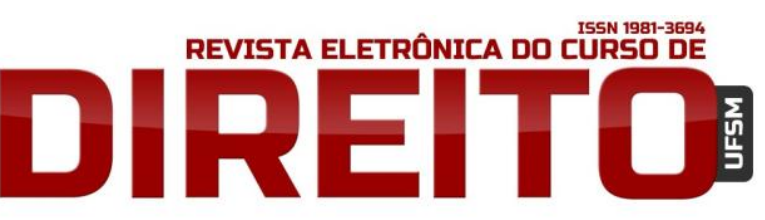

A DEMOCRATIZAÇÃO DA FAMÍLIA: SUBSTITUIÇÃO DA HIERARQUIA FAMILIAR PELA PARIDADE NAS RELAÇÕES CONJUGAIS E SUAS IMPLICAÇÕES PARA A FAMÍLIA BRASILEIRA CONTEMPORÂNEA

\section{SUMÁRIO}

INTRODUÇÃO; 1 BREVES CONSIDERAÇÕES HISTÓRICAS SOBRE A FORMAÇÃO DA FAMÍLIA BRASILEIRA; 2 CONCEITOS: FAMÍLIA E DEMOCRATIZAÇÃO; 2.10 fundamento que inspira a democratização da família; 3 DA HIERARQUIA FAMILIAR À PARIDADE NAS RELAÇÕES CONJUGAIS; 4 CAUSAS DO DECLÍNIO DO MODELO HEGEMÔNICO - PATRIARCALISMO; 4.1 Revolução Industrial e sua influência na estrutura familiar; 4.2 Movimento feminista; 4.3 Sexualidade: afeto, prazer e reprodução; 5 IMPLICAÇÕES DA DEMOCRATIZAÇÃO PARA A FAMÍLIA BRASILEIRA CONTEMPORÂNEA; CONCLUSÃO; REFERÊNCIAS.

\section{INTRODUÇÃO}

O Direito das Famílias é um dos ramos do Direito Privado que mais sofreu e vem sofrendo alterações no último século, em todo o mundo ocidental. Dentre os vários organismos sociais e jurídicos, o conceito, a compreensão e a extensão de família são os que mais se alteraram no curso dos tempos. Em poucas décadas, os paradigmas do Direito das Famílias foram diametralmente modificados e do modelo unitário de família passou-se à pluralidade de famílias.

O modelo tradicional conhecido como patriarcal cedeu lugar a uma extrema mobilidade das configurações familiares, o que provocou uma verdadeira democratização da estrutura familiar. O modelo convencional, composto por um homem e uma mulher, unidos pelo casamento e seus filhos, tem sido cada vez mais contestado.

A democratização da família dentro do contexto brasileiro teve seu marco histórico a partir da Constituição Federal de 1988 (CF), em que se estabeleceu a igualdade de direitos e deveres para homens e mulheres. No entanto, para que houvesse a democratização da família, sobretudo no que diz respeito à substituição da hierarquia familiar pela paridade nas relações conjugais, diversos fatores contribuíram para o afastamento da concepção hierárquica e matrimonial da família, dando lugar a uma família igualitária ou democratizada.

Os diversos arranjos familiares, decorrentes da própria evolução contemporânea da família, permitem já estabelecer um primeiro inventário de aspectos fundamentais dessa evolução e de problemas a estudar, por eles suscitados. A recusa da família do modelo tradicional anda assim acompanhada pela aspiração a uma nova forma de família. Mas, qual será a estrutura deste novo padrão de família? Quais serão aí os papéis dos seus membros?

O que se discute não é o desaparecimento da família tal como era tida antes da CF/88, mas sua profunda diversificação e a mudança do seu sistema de poder. Também se discute as 
implicações deste modelo democratizado para a família contemporânea, pois mudanças tão significativas provocam tensões e até mesmo novos problemas.

Pode-se afirmar que são nos planos dos valores e das concepções globais sobre o papel da mulher, a sexualidade e a conjugalidade, que as transformações dos últimos quarenta anos são mais significativas. A reivindicação da igualdade entre homens e mulheres reflete nas mudanças no plano legislativo e é inegável que a autonomia econômica feminina contribui para a defesa da democratização da família.

Este trabalho tem como objetivo demonstrar ao leitor que o Direito das Famílias requer um estudo abrangente, não somente no seu aspecto jurídico, como também sociológico, filosófico, psicológico e histórico. Isto porque, a família, como instituição, é capaz de remodelar sua estrutura a partir de costumes e valores morais a ela agregados.

Exige-se, portanto, que o operador do Direito seja conhecedor desses fatores, até mesmo porque o Direito se preocupa em tutelar as relações familiares, de acordo com o seu momento histórico. Em virtude disso, é necessário que todos aqueles que procuram focalizá-la em seus estudos ou trabalhos, tenham em mente que o Direito das Famílias deve ser compreendido historicamente, e de acordo com as suas especificidades.

A pesquisa realizada neste trabalho é bibliográfica e teórica, com levantamento documental, objetivando uma análise de doutrina, tendo como parâmetro, de forma principal, a CF/88 e a moderna doutrina do Direito das Famílias. 0 método utilizado foi o dedutivo, com análise de obras e sites relacionados ao tema e à legislação pertinente.

\section{BREVES CONSIDERAÇÕES HISTÓRICAS SOBRE A FORMAÇÃO DA FAMÍLIA BRASILEIRA}

A família brasileira se formou a partir do regime patriarcal e sob a influência da miscigenação de três culturas: indígena, europeia e africana. "Sendo assim, este processo propiciou a formação de uma população diferenciada que não pode negar a existência de traços culturais diversos". ${ }^{1}$ Assim como o povo brasileiro formou-se, também constituiu sua família.

A partir de traços culturais tão diversos, a família brasileira formou-se a partir de uma sociedade "agrária na estrutura, escravocrata na técnica de exploração econômica, híbrida de

1 MONCORVO, Maria Cecília Ribeiro. Criando os filhos sozinha: a perspectiva feminina da família monoparental. 2008. 106 f. Dissertação (Pós-Graduação em Psicologia) - Pontifícia Universidade Católica do Rio de Janeiro, Rio de Janeiro, p. 13. 
índio - e mais tarde de negro - na composição". ${ }^{2}$ A família patriarcal reunia em torno do patriarca um grande número de bastardos e dependentes. ${ }^{3}$ Assim, a família rural ou semi-rural foi constituída por pessoas casadas vindas do reino de Portugal, e outras, estabelecidas pela união de colonos com mulheres caboclas ou indígenas. Também moças foram trazidas de Portugal pelos padres casamenteiros para que mais casamentos fossem realizados. ${ }^{4}$

A família colonial brasileira reuniu, sobre a base econômica da riqueza agrícola e do trabalho escravo, uma variedade de funções sociais e econômicas, inclusive a do mando político: o oligarquismo ou nepotismo, que aqui madrugou, chocando-se com o clericalismo dos padres em meados do século XVI. ${ }^{5}$ Nesse contexto, desenvolveu-se uma estrutura social em que a família funcionava com um núcleo composto pelo chefe da família - patriarca, responsável por cuidar dos negócios e defender a honra da família. A família colonial, portanto, era bem hierarquizada, estando o homem no topo da pirâmide, a quem todos os demais se subordinavam.

É nesse período colonial que sobre o filho de família escravocrata no Brasil agiam influências sociais - a sua condição de senhor cercado de escravos, desenvolvia o gosto de mando violento ou perverso. Quando homem feito, transformava-se no homem amante pelo desejo de mandar dar surra; determinar arrancar dente de negro ladrão de cana, além de tantas outras atrocidades. $^{6}$

Esse desejo de mando violento se encontra refinado num senso grave de autoridade. Nada mais que um rude autoritarismo que resulta na ação persistente de conquistador sobre conquistado, de senhor sobre escravo. Fato ligado naturalmente à circunstância econômica da formação patriarcal, da mulher ser tantas vezes no Brasil vítima inerme do domínio ou do abuso do homem. ${ }^{7}$

A submissão e a resignação das mulheres mantinham os casamentos a qualquer custo. Seus desejos, portanto, eram negados e até mesmo sua identidade era retirada, ao adotar o sobrenome do marido, em nome de uma falsa fusão dos espíritos. ${ }^{8}$

\footnotetext{
${ }^{2}$ FREYRE, Gilberto. Casa grande \& senzala. Rio de Janeiro: José Olympio, 1933, p. 101.

${ }^{3}$ Ibid., p. 121

${ }^{4}$ Ibid., loc. cit.

${ }_{6}^{5}$ FREYRE, 1933, p. 121

${ }^{6}$ Ibid., p. 150

${ }^{7}$ Ibid., loc. cit.

${ }^{8}$ PEREIRA, Rodrigo da Cunha. Princípios fundamentais e norteadores para a organização jurídica da família. 2004. 157 f. Tese (Doutorado em Ciências Jurídicas) - Universidade Federal do Paraná, Curitiba. p. 105
} 
Apesar disso, a mulher é considerada a base física da família brasileira. Por seu intermédio enriqueceu-se a vida no Brasil. Foi ela quem desenvolveu uma série de alimentos ainda hoje em uso, de drogas e remédios caseiros, de tradições ligadas ao desenvolvimento da criança, de um conjunto de utensílios de cozinha, de processos de higiene tropical, inclusive o banho frequente ou pelo menos diário, que tanto deve ter escandalizado o europeu porcalhão do século XVI. ${ }^{9}$

Freyre afirma que era a mulher o principal valor econômico e técnico - "um pouco besta de carga e um pouco escrava do homem". Porém superior a ele na capacidade de utilizar as coisas e de produzir o necessário à vida e ao conforto comuns. ${ }^{10}$

Observa-se que a família no Brasil colônia é considerada uma instituição indispensável para a vida social. ${ }^{11}$

Aquele que não fizesse parte de um círculo familiar praticamente não sobreviveria socialmente, sendo mal visto, renegado ou ignorado. Neste momento histórico, a noção de indivíduo, na cultura brasileira, ainda não havia se enraizado, e o bem-estar social significava antes de tudo o pertencimento a algum grupo familiar. 0 vínculo familiar, era, portanto, cultuado como um valor indissolúvel e vigorava associado à ideia de prestígio social. Quem não tem família já desperta pena antes de começar o entrecho dramático; e quem renega sua família tem, de saída, a nossa mais franca antipatia. ${ }^{12}$

É importante ressaltar que, nos séculos XVI e XVII, a economia da colônia concentrava-se nas plantações de cana-de-açúcar localizadas no Nordeste do Brasil. Nesse contexto, os senhores de engenho chefiavam as famílias de elite as quais habitavam mansões, além de serem cercados por escravos e dependentes. Nas uniões legítimas o papel dos sexos estava bem definido, por costumes e tradições apoiados nas leis. Ao marido pertencia o poder de decisão indiscutível, bem como a tarefa de proteger e prover o sustento da esposa e filhos, cabendo à esposa o governo da casa e a assistência moral à família. ${ }^{13}$

0 modelo patriarcal foi considerado por várias gerações de estudiosos como critério e medida de valor para a compreensão da vida familiar ao longo do tempo. ${ }^{14} \mathrm{~A}$ dominância

\footnotetext{
9 FREYRE, op. cit. p. 225.

10 Ibid., op. cit.

11 DA MATTA, 1987, apud MONCORVO, 2008, p. 14.

12 Ibid. loc. cit.

${ }^{13}$ MONCORVO, 2008, p. 14.

14 Ibid., loc. cit.
} 
A DEMOCRATIZAÇÃO DA FAMÍLIA: SUBSTITUIÇÃO DA HIERARQUIA FAMILIAR PELA PARIDADE NAS RELAÇÕES CONJUGAIS E SUAS IMPLICAÇÕES PARA A FAMÍLIA BRASILEIRA CONTEMPORÂNEA

patriarcal ocorreu não somente na sociedade colonial, como também no período da independência, da República, e até mesmo na contemporaneidade brasileira. Como modelo dominante, serviu como referencial para as demais configurações familiares. ${ }^{15}$

Lôbo afirma que a legislação civil brasileira tomou como modelo a família patriarcal tanto no Brasil colônia, como também no império e durante boa parte do século XX. Tal modelo entrou em crise e culminou com sua derrocada, no plano jurídico, pelos valores introduzidos na $\mathrm{CF} / 88 .^{16}$

A família, ao longo dos tempos, passou por transformações as quais foram resultado direto das influências políticas, econômicas, sociais e culturais. Dessa forma, ocorreram profundas mudanças de função, natureza e estrutura, bem como alteração das funções de seus membros em seu interior.

\section{CONCEITOS: FAMÍLIA E DEMOCRATIZAÇÃO}

De acordo com Pontes de Miranda há diversidade quanto ao conceito de família. “A palavra "família", aplicada aos indivíduos, empregava-se no direito romano em acepções diversas. [...] se usava em relação às coisas, para designar o conjunto do patrimônio, ou a totalidade dos escravos pertencentes a um senhor". ${ }^{17}$ Esta palavra família, em um sentido especial, compreende o pai, a mãe e os filhos; e tomada em um sentido geral compreende todos os parentes. $^{18}$

O conceito de família no Código Civil:

Ora significa o conjunto das pessoas que descendem de tronco ancestral comum, tanto quanto essa ascendência se conserva na memória dos descendentes, ou nos arquivos, ou na memória dos estranhos; ora o conjunto de pessoas ligadas a alguém, ou a um casal, pelos laços de consanguinidade ou de parentesco civil; ora o conjunto das mesmas pessoas, mais os afins apontados por lei; ora o marido e a mulher, descendentes e adotados; ora, finalmente, marido, mulher e parentes sucessíveis de um e de outra. ${ }^{19}$

\footnotetext{
${ }^{15}$ Ibid., loc. cit.

${ }^{16}$ LÔBO, Paulo. Direito Civil: Famílias. 4. ed. São Paulo: Saraiva, 2011, p. 17.

17 PONTES DE MIRANDA, J. C. Tratado de direito de família. Atualizador Vilson Rodrigues Alves. Campinas: Bookseller, 2001. v 1, p.57.

18 lbid., p. 58

19 Ibid., p. 59
} 
O termo família aparece na $\mathrm{CF} / 88$, art. 226, afirmando que esta, enquanto base da sociedade tem especial proteção do Estado. Por esse dispositivo consagra-se que a convivência humana está estruturada a partir de cada uma das diversas células familiares que compõem a comunidade social e política do Estado, que por sua vez se encarrega de proteger e aperfeiçoar a família, como forma de fortalecer a sua própria instituição política. ${ }^{20}$ Lôbo afirma que "no plano constitucional, o Estado, antes ausente, passou a se interessar de forma clara pelas relações de família, em suas variáveis manifestações". ${ }^{21}$

Por outro lado, a democratização é definida como a 'irresistível tendência para transformar o casamento numa sociedade de tipo igualitário' ${ }^{22}$ Essa democratização sugere como a vida familiar deve combinar a escolha individual e a solidariedade social. Sob os critérios da democracia, a família contemporânea deve ser alicerçada sobre a igualdade, respeito mútuo, autonomia e tomada de decisão sem violência e por meio do diálogo.

Pode-se afirmar que a democratização da família teve seu marco histórico a partir da $\mathrm{CF} / 88$, onde se estabeleceu a igualdade de direitos e deveres para homens e mulheres. Mas até chegar a esse marco histórico, diversos fatores contribuíram para o afastamento da concepção hierárquica e matrimonial da família, dando lugar a uma família igualitária e plural.

Mas qual a fundamentação para a democratização da família? A fundamentação se baseia em princípios consagrados na Carta Política de 1988, especificamente nos artigos $5^{\circ}$, I e $226 \S 5^{\circ}$, I. A igualdade, portanto, constitui um dos princípios-chave para as organizações jurídicas e especialmente para o Direito das Famílias, conforme se observa abaixo.

\subsection{O fundamento que inspira a democratização da família}

A CF/88 consagrou o princípio da dignidade humana como um macroprincípio sob o qual irradiam e estão contidos outros princípios e valores sociais, dentre estes o da igualdade. ${ }^{23}$ Rolf Madaleno afirma que a igualdade entre todos se tornou preceito constitucional, explicitando a Carta Federal serem homens e mulheres iguais em direitos e obrigações. ${ }^{24}$ :

\footnotetext{
${ }^{20}$ MADALENO, Rolf. Curso de Direito de Família. 4 ed. Rio de Janeiro: Forense, 2011, p. 27.

${ }^{21}$ LÔBO, 2011, p. 17.

${ }^{22}$ CARBONIER apud GOMES, Orlando. Direito de Família. Atualizador Humberto Theodoro Júnior. $11^{\mathrm{a}}$ ed. Rio de Janeiro: Forense, 1999, p. 12.

${ }^{23}$ PEREIRA, 2004, p. 68.

${ }^{24}$ MADALENO, Rolf. A desigualdade conjugal do código civil. Revista do Advogado: Família e Sucessões. São Paulo. Ano 31. n. 112, jul. 2011. p. 153.
} 
Essa igualdade dos cônjuges e não só deles, pois a igualdade é das pessoas, e nem mais precisa ser civilmente casado para merecer tratamento igualitário nas relações afetivas; é sobretudo, uma isonomia ostentada no fundamento supremo do Estado Democrático de Direito da Carta da República brasileira, de defesa da dignidade humana, traduzida pela solidariedade econômica dos cônjuges, que passam a contribuir com o seu trabalho no atendimento das necessidades do seu grupo familiar e outras diretivas também proclamadas pelo calor da progressão isonômica, mas contestadas no mundo axiológico pelo contrafluxo de evidências que, lamentavelmente, ainda apontam e sinalizam para a existência de uma distância abismal da desejada paridade. ${ }^{25}$

Pereira afirma que a igualdade de todos perante a lei, como ideia iluminista, reforçada pela Revolução Francesa e pelas declarações de direitos do homem, deve ser repensada. Ou seja, a igualdade dos gêneros deve, antes, considerar a diferença que há entre eles. ${ }^{26}$ Assim, a igualdade e o respeito às diferenças é imperativo para o Direito das Famílias, sem os quais não há dignidade do sujeito de direito, consequentemente não há justiça.

\section{DA HIERARQUIA FAMILIAR À PARIDADE NAS RELAÇÕES CONJUGAIS}

Pereira, em sua tese, afirma que a "história da organização jurídica da família moderna assenta-se em princípios que foram construídos e desconstruídos através de uma ideologia movente ao longo dos séculos" ${ }^{27}$. Aspectos políticos e econômicos davam o tom patrimonializado e hierarquizado às famílias ocidentais. Também se assentava sob uma moral que dizia o deverser, além de sustentar a ideologia patriarcal através de uma moral sexual civilizatória. ${ }^{28}$

Havia uma hierarquia na estrutura familiar. A família compreendia o pater famílias, ou seja, havia um chefe, os descendentes ou não eram submetidos ao pátrio poder, e a mulher se considerava em condição análoga à de uma filha. ${ }^{29}$ A relação conjugal imitava a relação estatal com os cidadãos, de natureza hierárquica e moldada sobre o binômio autoridade-submissão, e tinha como palavras de ordem: poder doméstico, controle marital e obediência da mulher. ${ }^{30}$

${ }^{25}$ MADALENO, 2011, p. 43.

26 PEREIRA, Rodrigo da Cunha. Direito de Família: uma abordagem psicanalítica. Belo Horizonte: Del Rey, 1997, p. 107.

${ }_{27}$ PEREIRA, 2004, p. 52.

28 Ibid., loc. cit.

29 PONTES DE MIRANDA, 2001, v 1. p. 58.

30 SAAD, Martha Solange Scherer. A evolução jurídica da mulher na família. In: BERTOLIN, Patrícia Tuma Martins, ANDREUCCI, Ana Cláudia Pompeu Torezan (Org.). Mulher sociedade e direitos humanos. São Paulo: Rideel. 2010, p.10. 


\section{(2)

A DEMOCRATIZAÇÃO DA FAMÍLIA: SUBSTITUIÇÃO DA HIERARQUIA FAMILIAR PELA PARIDADE NAS RELAÇÕES CONJUGAIS E SUAS IMPLICAÇÕES PARA A FAMÍLIA BRASILEIRA CONTEMPORÂNEA

A posição jurídica do marido colocava-o como o chefe da sociedade conjugal conforme dispõe o art. 233 do Código Civil brasileiro de 1916 (CC/1916). Assim, possuía o direito a ser atendido pela mulher, devendo essa, no que seja justo e honesto, moldar suas ações pela vontade dele. ${ }^{31} \mathrm{~A}$ família dirigida pelo seu chefe cumulava as funções jurídicas e políticas. Assim, foi um instrumento de governo na sociedade e o Estado apoiava-se nos chefes dessas famílias. ${ }^{32}$

Samara afirma que o pátrio poder era, portanto, a pedra angular da família e emanava do matrimônio. ${ }^{33} \mathrm{O}$ patriarca dominava com autoridade absoluta incontestável e influenciava a política, a economia, alcançando por fim todas as esferas da sociedade. ${ }^{34}$

Cabia ao marido o direito, dentre outros, o de autorizar a profissão da mulher e sua residência fora do teto conjugal. A mulher podia ter profissão, no entanto, para exercê-la necessitava de assentimento marital, sob a justificativa de que a profissão trazia encargos comuns para os quais era necessário em princípio, autorização marital, a fim de que tivessem valor jurídico. ${ }^{35}$

Importante jurisprudência da Corte de Apelação do Espírito Santo, de 13 de novembro de 1936, RT 113/776 merece ser citada:

[...] cabe ao Código Civil estabelecer as normas concernentes à capacidade da mulher casada. No Título II, Do Direito de Família, ocupa-se dos efeitos jurídicos do casamento. Entre esses está o direito que cabe ao marido de autorizar a profissão da mulher, art. 233, IV, 242, VII. O Código exige que essa autorização conste de instrumento público, ou particular, devidamente autenticado; abre, porém, exceção quando a mulher ocupa cargo público ou, por mais de seis meses, se entrega à profissão exercida fora do lar conjugal, art. 247, parágrafo único. ${ }^{36}$

Cabia também ao marido a obrigação de sustentar a mulher. Pontes de Miranda traz em sua obra, decisão da $4^{\text {a }}$ Câmara do Tribunal de Apelação de São Paulo, em 19 de fevereiro de 1945, na qual diz o seguinte:

31 PONTES DE MIRANDA, 2001, v. 2, p. 39.

32 HENRI-PAUL; LAUWE, Maria José Chombart de. A evolução contemporânea da família: estruturas, funções, necessidades. ICS.UL, Lisboa, 2013, Disponível em: <analisesocial.ics.ul.pt/.../1224165225Z5aRR5fx5Sc98EV6.pdf>. Acesso em $18 \mathrm{de}$ fev de 2013.

${ }^{33}$ SAMARA, Eni de Mesquita. O que mudou na família brasileira? (da colônia à atualidade). Psicologia USP. São Paulo, v 13, n 2, 2002.

${ }^{34}$ Ibid., loc. cit.

${ }^{35}$ PONTES DE MIRANDA, 2001, v 2, p. 42.

${ }^{36}$ Ibid., p. 72. 
Ainda que não tenha sido intentada ação de desquite pela mulher, ao marido, como chefe da sociedade conjugal, cumpre mantê-la e sustentá-la (Código Civil, art. 233, $n^{\circ}$ V). Tal obrigação só cessa, para o marido, nos termos do art. 234 do Código Civil, quando a mulher, sem justo motivo, abandona a habitação conjugal e a esta se recusa a voltar. Quando é o marido quem deserta o lar conjugal, pode a mulher exigir alimentos. ${ }^{37}$

Para Pontes de Miranda, a limitação à situação da mulher casada é decorrente de criações da lei, e não-limitações fundadas em incapacidade ou infirmeza de caráter, nem tampouco, na inferioridade de sexo. É criação da lei por motivos de interesses públicos da família. 0 assentimento uxório que o marido necessita para certos atos constitui prova de que as limitações à situação da mulher casada não são derivadas das qualidades físicas ou psíquicas do sexo feminino, mas resultantes da instituição social do matrimônio. ${ }^{38}$

Para este doutrinador, a mulher não era no CC/1916, sistematicamente, considerada “incapaz". Se assim o fosse, incapaz seria o marido, que também necessita, para certos atos, do assentimento dela. ${ }^{39} 0$ que se dá, argumenta, é que existindo a sociedade conjugal, impersonificada, alguém há de ter a direção e a administração do casal, e a lei as confere ao marido. A mulher não era incapaz, pois na falta do marido, era a mulher que assumia a direção e a administração do casal. ${ }^{40}$

O fato é que, mesmo com a incorporação massiva das mulheres solteiras e jovens no mercado de trabalho e as atividades domiciliares continuarem permitindo que as casadas contribuíssem para a renda familiar, sem, no entanto, deixarem de exercer as funções básicas de mãe e de donas de casa, para as quais tinham sido socializadas e educadas ${ }^{41}$, ainda assim, a legislação reforçou o privilégio masculino.

Para Samara, apesar da República e das mudanças que estavam ocorrendo,

a vida continuou girando em torno da família e que a legislação reforçou, uma vez mais, o privilégio masculino. O marido continuava, legalmente, com a designação de chefe de família, como no velho Código Filipino (1870), compilado em Portugal em 1603. O Código Civil de 1916 reconheceu e legitimou a supremacia masculina, limitando o acesso feminino ao emprego e à propriedade.

\footnotetext{
37 PONTES DE MIRANDA, 2001 v.1, p. 43

38 PONTES DE MIRANDA, op. cit. p. 63.

39 PONTES DE MIRANDA, 2001, v 2, p. 105.

40 Ibid., loc. cit.

41 SAMARA, 2002.
} 
As mulheres casadas ainda eram, legalmente, incapacitadas e apenas na ausência do marido podiam assumir a liderança da família. ${ }^{42}$

A família patriarcal era, portanto, a espinha dorsal da sociedade e desempenhava os papéis de procriação, administração econômica e direção política. É a imagem mais representativa no Brasil. Vista no contexto da história brasileira como uma instituição que impôs normas e valores morais desde o Brasil colônia. A própria legislação do Brasil Republicano reconheceu e legitimou a família patriarcal. O CC/1916 retratava a sociedade da época, que era extremamente conservadora e patriarcal. O comando era exclusivo do homem, transformando-o em autoridade com poder pessoal.

Pontes de Miranda, ao tratar da simetrização entre homem e mulher, afirma que o jurista de 1916 não pôde reduzir as desigualdades que persistiam entre o homem e a mulher. ${ }^{43}$

Com as consequências da guerra europeia, as circunstâncias da vida mudaram sensivelmente. Exigências materiais impuseram à mulher teor diferente de atividade. Não seria possível que isso se não refletisse na elaboração do direito depois da legislação civil de 1916. A Constituição de 1934, no art. 113, 1, frisava não haver privilégios, nem distinções, por motivo de sexo. ${ }^{44}$

Embora a Constituição de 1934 frisasse não haver distinções por motivo de sexo, o fato é que a discriminação em decorrência dos gêneros sexuais era uma realidade. Não se havia rompido com o modelo da supremacia masculina no governo da unidade familiar. Percebe-se que a evolução do direito é lenta e a modificação da legislação não é suficiente para extirpar profundos preconceitos quanto aos direitos da mulher.

Em 1988 foi proclamada pela Carta Política brasileira a completa paridade jurídica dos gêneros sexuais. Madaleno afirma que

Começou a desconstruir a ideologia da família patriarcal, edificada em uma família monogâmica, parental, patriarcal e que reinou absoluta na sociedade brasileira, herdada dos patriarcas antigos e dos senhores medievais. ${ }^{45}$

A partir da CF/88, a condição da mulher é a de sócia do homem, e não escrava. Mas, mesmo após o advento da CF/88, especialmente no seu art. $226, \S 5^{\circ}$, onde se estabeleceu a

\footnotetext{
42 Ibid., loc. cit.

43 PONTES DE MIRANDA, 2001, v 1. p. 50

${ }^{44}$ Ibid., loc. cit.

${ }^{45}$ MADALENO, 2011, p. 5.
} 


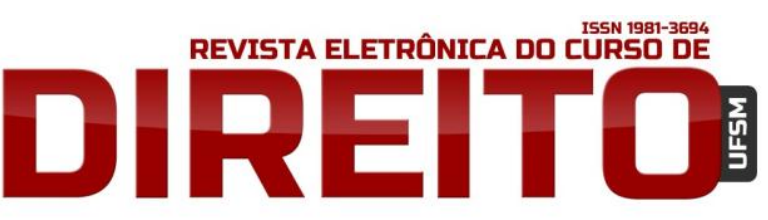

A DEMOCRATIZAÇÃO DA FAMÍLIA: SUBSTITUIÇÃO DA HIERARQUIA FAMILIAR PELA PARIDADE NAS RELAÇÕES CONJUGAIS E SUAS IMPLICAÇÕES PARA A FAMÍLIA BRASILEIRA CONTEMPORÂNEA

completa paridade jurídica dos gêneros sexuais e igualdade entre os cônjuges ou conviventes, Reis afirma ser relativo este princípio, porque é “inerente a qualquer grupo social a existência de um comando decisório, diante da possibilidade de divergência entre seus membros" ${ }^{\text {46 }}$. A conclusão doutrinária de Reis é que não poderia ser diferente em relação à sociedade conjugal, devendo os interesses do matrimônio seguir os ditames naturais, que concentram em um só dos cônjuges a direção dos desígnios da família ${ }^{47}$.

Para o doutrinador Chaves, em toda e qualquer sociedade deve haver um chefe, na sociedade conjugal não seria diferente. 0 mais justo, em pura teoria, fora talvez que assumisse a direção o marido ou a mulher, conforme eles próprios convencionassem ${ }^{48}$. Considera mais útil a chefia do marido, por vários fatores, de ordem social, física e psíquica ${ }^{49}$. Embora reconheça que possa acontecer que, em determinada família, tenha a mulher manifesta superioridade, que a indique como mais capaz para a direção da sociedade. ${ }^{50}$

O fato é que a CF/88 estabeleceu princípios gerais de proteção da família, especialmente a da igualdade entre os cônjuges. Foi reconhecida a completa paridade entre os cônjuges, desaparecendo a hipocrisia de o marido exercer a chefia da sociedade conjugal e de a mulher ser sua mera colaboradora. ${ }^{51}$

A reivindicação da igualdade para as mulheres foi refletida em mudanças legislativas significativas. Para exemplificar, constata-se o desaparecimento da figura do chefe de família no CC/2002. Homem e mulher são responsáveis pela proteção e educação dos filhos, e ambos têm os mesmos direitos e deveres.

\section{CAUSAS DO DECLÍNIO DO MODELO HEGEMÔNICO - PATRIARCALISMO}

É preciso evocar as causas e os fatores determinantes do declínio do modelo hegemônico que contribuíram, nos últimos tempos, para a transformação da família, para que assim possa compreender a razão de certas mudanças e quais implicações trarão para a família

\footnotetext{
${ }^{46}$ REIS, 1994 apud MADALENO. jul. 2011. p. 152.

${ }^{47}$ Ibid., loc. cit.

${ }^{48}$ CHAVES, Antônio. Direito de Família: Tratado de Direito Civil. 2. ed. São Paulo: Revista dos Tribunais, 1991, v. 5, p. 293.

${ }^{49}$ Ibid., loc. cit.

${ }^{50}$ Ibid., loc. cit.

${ }^{51}$ MADALENO, 2011, p. 34.
} 
contemporânea. Como uma unidade orgânica, a família deve ser examinada sob o ponto de vista sociológico, antes de ser analisada como fenômeno jurídico.

Segundo o sociólogo Castells, “o patriarcalismo é caracterizado pela autoridade, imposta institucionalmente, do homem sobre a mulher e filhos no âmbito familiar." 52

As mulheres não tinham visibilidade fora do lar conjugal e suas vidas simplesmente eram confinadas no recesso do lar. As solteiras eram consideradas aptas para certos empregos como professoras, enfermeiras, babás, cozinheiras e serventes. As casadas, só trabalhavam fora do ambiente doméstico quando em situações de subsistência da sua própria família, seu marido encontrava-se ausente ou enfermo, incapaz, portanto de suprir as necessidades da família. ${ }^{53}$

No entanto, foi com as duas guerras mundiais que o trabalho feminino foi convocado para preencher o enorme vazio verificado no mercado de trabalho com os homens ocupando o front das batalhas. Porém, afirma Madaleno que estas guerras não foram suficientes para afastar das leis a discriminação em decorrência dos gêneros sexuais e o modelo de supremacia masculina no governo da unidade familiar prevalecia. ${ }^{54}$

Para que a democratização da família de fato ocorresse, diversas causas contribuíram para a derrocada do modelo hegemônico. Logo, é necessário analisar algumas delas: a Revolução Industrial, o movimento feminista e a questão da sexualidade feminina, as quais representam os mecanismos sociais que vinculam a crise da família patriarcal, e a redefinição social da vida familiar e, consequentemente a mudança do seu sistema de poder.

\subsection{Revolução Industrial e sua influência na estrutura familiar}

Para entender as mudanças que a Revolução Industrial trouxe para o âmbito das famílias, necessário se faz ponderar sobre a família antes da Revolução Industrial.

No período colonial, as famílias viviam em fazendas ou em aldeias rústicas. 0 trabalho produtivo era feito em casa ou em seus anexos e era realizado pelas famílias e não por indivíduos isolados. Uma casa era uma unidade econômica relativamente autônoma, abrangendo parentes, aprendizes, criados. Lojas, escritórios e oficinas ficavam na parte da frente da casa,

\footnotetext{
${ }^{52}$ CASTELLS, Manuel. 0 poder da identidade. 6 ed. São Paulo: Paz e Terra, 2008, v. 2, p. 169.

${ }^{53}$ MADALENO, 2011, p. 152.

54 Ibid., loc. cit.
} 
enquanto a família morava em cima ou nos fundos. Cada negócio era um genuíno empreendimento familiar. ${ }^{55}$

Nessa trajetória histórica, trabalho e família passaram por profundas transformações em virtude da incorporação das mulheres no mercado de trabalho remunerado.

Para Venosa, a família monogâmica converte-se em um fator econômico de produção, pois se restringe quase exclusivamente aos interiores dos lares, nos quais existem pequenas oficinas $^{56}$. Para o citado autor, a Revolução Industrial traz transformações econômicas e é neste contexto que ocorre a transição da família como unidade econômica para uma compreensão igualitária. A transformação da sociedade rural-patriarcal para sociedade de bases industriais.

\begin{abstract}
Ao tempo em que a economia doméstica estava concentrada no meio rural, a família já foi mais ampla e abrangia um espectro maior de parentes em linha reta e colateral, mas foi sendo reduzida, resumindo-se numericamente aos pais e filhos, com a sua migração para os centros urbanos, na busca de emprego na indústria em franca expansão, ao mesmo tempo em que estabelecia a ocupação da família restrita de pequenos espaços para a moradia dos parentes em linha reta e em bastante proximidade de graus. ${ }^{57}$
\end{abstract}

Com o advento da sociedade industrial, os homens foram aprisionados no espaço da produção e o emprego de mulheres foi tratado como complementar. Assim, a economia política estimulou a divisão sexual, na qual cada sexo tem sua função, suas regras e seus espaços. ${ }^{58}$

Com o início da Revolução Industrial, houve um súbito enxugamento da família, que migrou do campo para os grandes centros industriais, e assim reduziu a quantificação dos seus componentes. ${ }^{59} \mathrm{Na}$ busca de emprego na indústria, a família migrou-se para os centros urbanos e houve a incorporação das mulheres no mercado de trabalho remunerado o que gerou consequências importantes na família.

A contribuição financeira das mulheres é decisiva para o orçamento doméstico. Em virtude disso, o poder de barganha da mulher no ambiente doméstico cresceu significativamente. Consequentemente, com as mulheres contribuindo financeiramente para o

\footnotetext{
${ }^{55}$ PEARCEY, Nancy. Como as mulheres começaram a guerra cultural. In: Verdade absoluta. Rio de Janeiro: CPAD, 2006. Cap. 12, p. 365

${ }^{56}$ VENOSA, Silvio de Salvo. Direito Civil: Direito de Família. 5. ed. São Paulo: Atlas, 2005. v. 6, p. 18

${ }^{57}$ MADALENO, 2011, p. 28.

${ }^{58}$ PICKINA, Eugênia M. V. Araújo. O público e o privado. In: BERTOLIN, Patrícia Tuma Martins, ANDREUCCI, Ana Cláudia Pompeu Torezan (Org.). Mulher sociedade e direitos humanos. São Paulo: Rideel. 2010, p.107.

${ }^{59}$ MADALENO, op. cit. p. 35.
} 
sustento da família, a ideologia do patriarcalismo, isto é, dominação com base na ideia de que o provedor da família deve gozar de privilégios, ficou terminantemente abalada. A questão que se deflui é: Por que não deveriam os homens ajudar nas tarefas domésticas se os dois membros do casal trabalham fora durante horas e ambos contribuem para o sustento da família? ${ }^{60}$

Ao mesmo tempo em que as mulheres assumiram trabalho remunerado, afazeres domésticos, criação de filhos e bem-estar dos maridos, elas perceberam que seus maridos/pais estavam aproveitando-se delas. É nesse contexto, que as sementes das ideias feministas germinavam no sentido de redefinir o gênero feminino em oposição direita ao patriarcalismo.

\subsection{Movimento feminista}

A história do movimento feminista possui três grandes momentos. 0 primeiro foi motivado pelas reivindicações por direitos democráticos como o direito ao voto, divórcio, educação e trabalho, no fim do século XIX. O segundo, no fim da década de 1960, foi marcado pela liberação sexual. Já o terceiro começou a ser construído no fim dos anos 70 , com a luta de caráter sindical. $^{61}$

O movimento feminista, manifestado na prática e em diferentes discursos, é extremamente variado. ${ }^{62} 0$ movimento feminista contemporâneo irrompeu primeiro nos Estados Unidos no final dos anos 60 e depois na Europa no início da década de 70, difundindo-se pelo mundo inteiro nas duas décadas seguintes. ${ }^{63}$

A história do feminismo como tal é antiga, como bem exemplificado pelo movimento sufragista nos Estados Unidos. Tenho, porém, de admitir que foi apenas nos últimos 25 anos que observamos uma insurreição maciça e global das mulheres contra sua opressão, embora com diferente intensidade dependendo da cultura e do país. Tais movimentos tem causado impacto profundo nas instituições da sociedade e, sobretudo, na conscientização das mulheres. [...] Essa é a mais importante das revoluções, porque remete às raízes da sociedade e ao âmago no nosso ser. ${ }^{64}$

\footnotetext{
${ }^{60}$ CASTELLS, 2008, p. 210

${ }^{61}$ MOVIMENTO feminista. Brasil.gov, Brasília, 2013. Disponível em: <http://www.brasil.gov.br/secoes/mulher/atuacao-feminina/feminismo-pela-igualdade-dos-direitos>. Acesso em: 06 mar. 2013.

${ }^{62}$ CASTELLS, 2008, p. 210.

${ }^{63}$ Ibid., loc. cit.,

64 lbid., p. 170.
} 


\title{
政

A DEMOCRATIZAÇÃO DA FAMÍLIA: SUBSTITUIÇÃO DA HIERARQUIA FAMILIAR PELA PARIDADE NAS RELAÇÕES CONJUGAIS E SUAS IMPLICAÇÕES PARA A FAMÍLIA BRASILEIRA CONTEMPORÂNEA

A essência do feminismo nega a identidade da mulher conforme definida pelos homens e venerada na família patriarcal. ${ }^{65}$ Existe um "esforço histórico, individual ou coletivo, formal ou informal, no sentido de redefinir o gênero feminino em oposição direta ao patriarcalismo". ${ }^{66}$ Seu ponto crucial é a defesa dos direitos da mulher. Positivamente é uma extensão do movimento dos direitos humanos. Isso inclui a afirmação básica das mulheres como seres humanos e não como bonecas, objetos, coisas, ou animais.

Portanto, os direitos da mulher são reivindicados em seu nome como ser autônomo, independentemente do homem e do papel que lhe cabe sob o patriarcalismo.

\begin{abstract}
A essência do feminismo, como praticado e relatado, é a (re)definição da identidade da mulher: ora afirmando haver igualdade entre homens e mulheres, desligando do gênero diferenças biológicas e culturais; ora, contrariamente, afirmando a especificidade essencial da mulher, frequentemente declarando, também, a superioridade das práticas femininas como fontes de realização humana; ou ainda declarando a necessidade de abandonar o mundo masculino e recriar a vida, assim como a sexualidade, na comunidade feminina. ${ }^{67}$
\end{abstract}

O patriarcalismo foi fortemente contestado pelo movimento feminista, seja lutando pelos direitos da mulher, seja desmistificando o discurso patriarcal, o que sem dúvida trouxe transformações da personalidade e da estrutura familiar. ${ }^{68}$

No Brasil, o movimento feminista foi a grande revolução do século XX. Esta revolução teve seu marco inicial na década de 60, cujas consequências começaram a dar sinais na legislação sobre a família, especialmente com a Lei $\mathrm{n}^{\circ} 4.121 / 64$, denominada de Estatuto da Mulher Casada. $(E M C)^{69}$ Esse diploma legislativo procedeu a diversas alterações no CC/1916: elevou a mulher casada à plenitude da capacidade jurídica, conferiu a direção moral e material da família, permitiu escolher pelo acréscimo do sobrenome e a igualou com o marido, às situações em que se fazia necessária a autorização conjugal. ${ }^{70}$ Só vinte e seis anos depois, com o advento da CF/88, a paridade nas relações conjugais foi finalmente alcançada.

\footnotetext{
${ }^{65}$ MADALENO, 2011. p. 35.

${ }^{66}$ CASTELLS, op. cit., p. 211.

67 Ibid., loc. cit.

${ }^{68}$ CASTELLS, 2008, p. 170.

${ }^{69}$ PEREIRA, 2004, p. 12

70 SAAD, 2010. p. 28.
} 


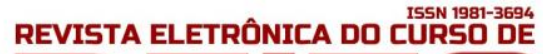

A DEMOCRATIZAÇÃO DA FAMÍLIA: SUBSTITUIÇÃO DA HIERARQUIA FAMILIAR PELA PARIDADE NAS RELAÇÕES CONJUGAIS E SUAS IMPLICAÇÕES PARA A FAMÍLIA BRASILEIRA CONTEMPORÂNEA

Fruto da articulação do movimento feminista no Brasil foi a "Carta das Mulheres Brasileiras aos Constituintes". ${ }^{71}$ Esta carta contribuiu para a redação de vários dispositivos constitucionais, dentre estes, a igualdade geral entre homens e mulheres (art. 5, I), a proteção contra a discriminação no trabalho por sexo ou estado civil (art. $7^{\circ}, \mathrm{XX}$ ), a licença- maternidade ampliada para 120 dias (art. $\left.7^{\circ}, \mathrm{XVIII}\right)$, os direitos inerentes à sociedade conjugal, exercidos pelo homem e pela mulher (art. 226, § $5^{\circ}$ ).

O movimento feminista continua atuando. Evento importante a ser destacado é a da resolução da Assembleia Geral da Organização das Nações Unidas, de 2 de julho de 2010. Aprovou-se, por unanimidade, a criação de uma nova entidade para acelerar o progresso na satisfação das necessidades das mulheres no mundo inteiro. ${ }^{72}$ "A Entidade das Nações Unidas para a lgualdade de Gênero e Empoderamento da Mulher (United Nations Entity for Gender Equality and the Empowerment of Women - UN WOMEN), a ser conhecida como "ONU Mulheres" "73 Esta entidade tem como finalidade aumentar significativamente os esforços das Nações Unidas para promover a igualdade de gênero, expandir as oportunidades e combater a discriminação em todo o globo. ${ }^{74}$

No Brasil, o movimento feminista pode contar com os esforços da Secretaria de Políticas das Mulheres, vinculada à Presidência da República, com status ministerial. Sua pauta de reivindicações para o século XXI incluem vários pontos, tais como a descriminalização do aborto como um direito de cidadania e também como questão de saúde pública e reconhecimento do direito das mulheres sobre a gestação, com acesso de qualidade à concepção e/ou contracepção.

O movimento feminista brasileiro avançou na conquista da cidadania feminina. A efetivação das ideias libertárias feministas na sociedade brasileira evidenciou mudanças culturais expressas nos avanços legislativos voltados a maior igualdade entre homens e mulheres, sobretudo na substituição da hierarquia familiar pela paridade nas relações conjugais, embora a conquista definitiva da igualdade entre homens e mulheres ainda está por vir.

71 COSTA, Claudia. Princípios constitucionais, igualdade e mulheres na Constituição de 1988 . In: BERTOLIN, Patrícia Tuma Martins, ANDREUCCI, Ana Cláudia Pompeu Torezan (Org.). Mulher sociedade e direitos humanos. São Paulo: Rideel. 2010, p.86.

${ }^{72}$ IBGE: Síntese de Indicadores Sociais. Uma análise das condições de vida da população brasileira 2010. Estudos e Pesquisas, Informação Demográfica e Socioeconômica. IBGE, 2013 Disponível em: http://www.ibge.gov.br/home/estatistica/populacao/condicaodevida/indicadoresminimos/sinteseindics ociais2010/SIS_2010.pdf. Acesso em: 07 mar. 2013. p. 250.

${ }^{73}$ Ibid., loc. cit.

${ }^{74}$ Ibid., loc. cit. 


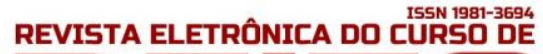

\subsection{Sexualidade: afeto, prazer e reprodução}

$\mathrm{Na}$ família patriarcal, os aspectos emocionais e afetivos não importavam para a sua constituição. Foi só ao final do século XIV e início do XV que se iniciou, embora timidamente, a compreensão de que seria legítima a atividade sexual entre marido $e$ mulher independentemente da finalidade procriativa. ${ }^{75}$ Tal compreensão decorre do pensamento teológico inspirado nas ideias de Johannes Gerson que se inclinou a admiti-la para impedir a prática da infidelidade. "Buscou-se evitar, dos pecados, o que talvez fosse o menor: legitimar o sexo sem prole". ${ }^{76}$

A situação sexual da mulher, segundo Shere, é explorada de forma inescrupulosa. Ela afirma que o governo americano permitiu a venda da revista Playboy em bancas, quando o Vietnã começava a inquietar o povo, era uma forma de entretenimento. ${ }^{77}$

A revolução sexual não foi revolução nenhuma, mas sim reação. Reação comercial, vulgar, tornando os corpos femininos acessíveis antes do casamento. Sexo é boa distração quando o povo está infeliz ou explorado.

A inserção da mulher no mercado e a preocupação com a carreira profissional trouxe outros problemas. Quem então cuidaria das crianças? É por isso que ficou tão importante as feministas ganharem controle de sua vida reprodutiva através da contracepção e do aborto.

Hodiernamente, o acesso aos métodos contraceptivos possibilita a livre opção de gerar filhos, pois a liberdade do casal para estabelecer um planejamento familiar é direito assegurado constitucionalmente (CF/88, art. 226, § 7).

A procriação não mais provém só da natureza, mas também da intervenção direta e exclusiva da vontade humana. A atividade sexual é um complemento da vida a dois, e não pode ser confundida com a finalidade do casamento ou com dever conjugal. ${ }^{78}$

A atividade sexual no casamento está inserida no dever de coabitação previsto no art. 1.566 do CC/2002, que não constitui, como entendem alguns, um dever legal e exigível. Ressalte-se que a imposição de um dos cônjuges ao outro não

\footnotetext{
75 SAAD, 2010.p. 20.

76 Ibid., loc. cit.

77 SHERE, Hite. Contra os favores do homem: a visão de uma feminista que procura destruir mitos sobre a vida sexual da mulher. Veja,São Paulo, 1978. Seção Páginas Amarelas. Disponível em:<http://veja.abril.com.br/acervodigital/home.aspx> . Acessoem 18 set. 2012.

${ }^{78}$ SAAD, op. cit. p. 25.
} 


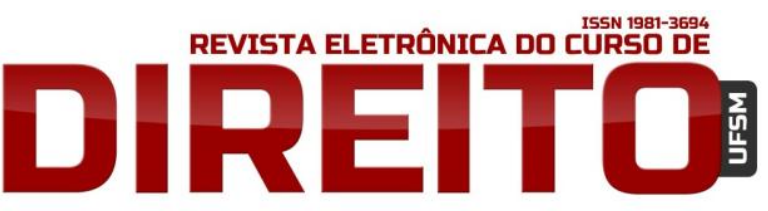

A DEMOCRATIZAÇÃO DA FAMÍLIA: SUBSTITUIÇÃO DA HIERARQUIA FAMILIAR PELA PARIDADE NAS RELAÇÕES CONJUGAIS E SUAS IMPLICAÇÕES PARA A FAMÍLIA BRASILEIRA CONTEMPORÂNEA

mais se considera exercício de um direito reconhecido, e, sim, estupro; caracteriza-se infração ao dever de respeito, viola o princípio constitucional da dignidade humana. ${ }^{79^{3}}$

Em virtude da procriação não ser mais o fim último do casamento, as pesquisas comprovam o declínio da fecundidade na sociedade brasileira. Segundo o IBGE, em 2009, a taxa de fecundidade total (número médio de filhos que uma mulher teria ao final do seu período fértil) foi de 1,94 filho. Tal valor revela o resultado de um processo intenso e acelerado de declínio da fecundidade ocorrido nas últimas décadas. Essa redução expressiva reflete a mudança que vem ocorrendo no Brasil em especial com a urbanização e com a entrada da mulher no mercado de trabalho. Os níveis mais baixos de fecundidade se encontram nos estados da região Sudeste, sobretudo no Rio de janeiro e Minas Gerais com valores um pouco acima de 1,60 filho por mulher. ${ }^{80}$ (Fig. 1).

Figura 1. Taxa de fecundidade total, segundo as Unidades da Federação 2009

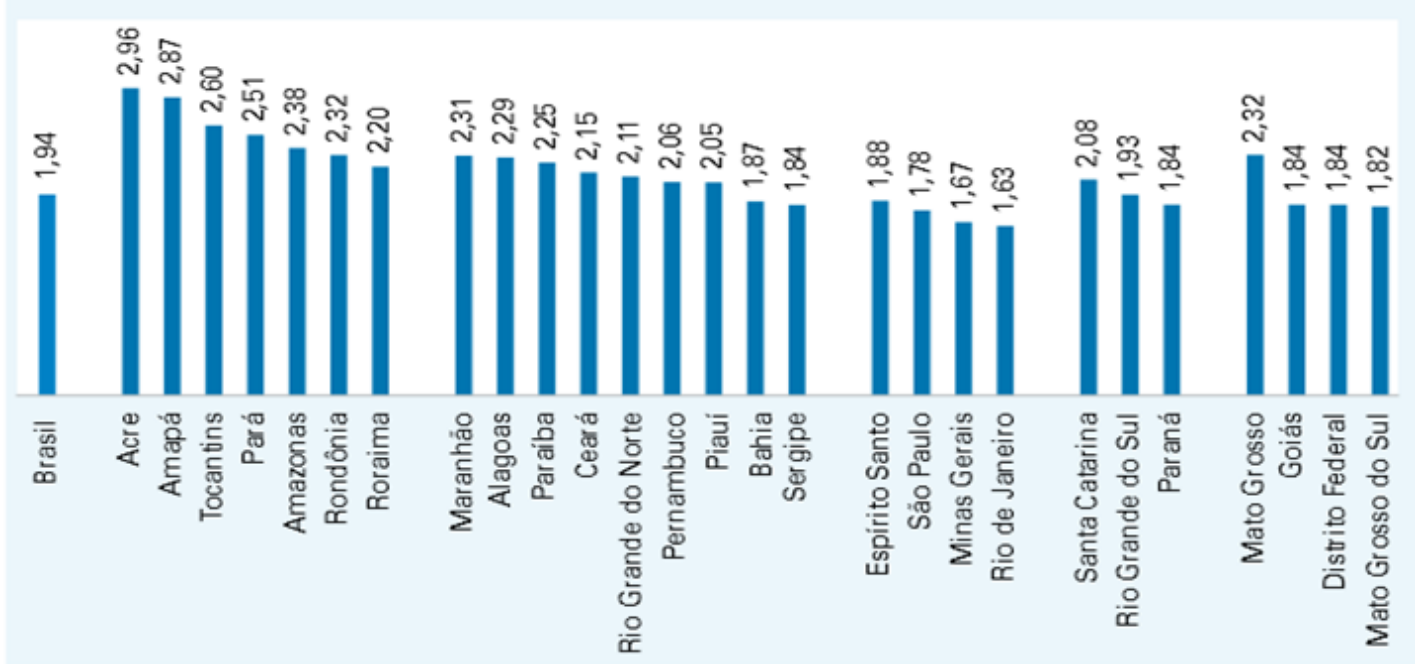

Fonte: IBGE, Pesquisa Nacional por Amostra de Domicílios (2009) apud IBGE (2013)

É preciso refletir sobre esta nova ideologia. Ideologia que proclama o direito exclusivo do prazer e atribui caráter repressivo e castrador aos deveres é dissolvente para o equilíbrio e sobrevivência de uma instituição como a família. Isto porque a família está baseada na

\footnotetext{
${ }^{79}$ Ibid, p. 24.

${ }^{80}$ IBGE, 2013, p. 29-30.
} 


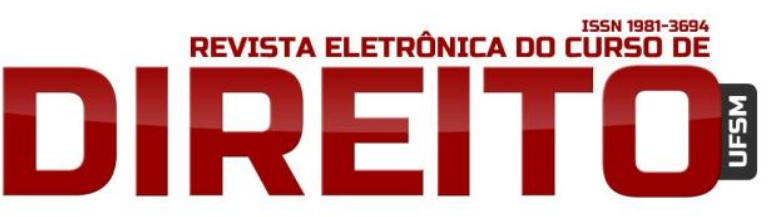

A DEMOCRATIZAÇÃO DA FAMÍLIA: SUBSTITUIÇÃO DA HIERARQUIA FAMILIAR PELA PARIDADE NAS RELAÇÕES CONJUGAIS E SUAS IMPLICAÇÕES PARA A FAMÍLIA BRASILEIRA CONTEMPORÂNEA

reciprocidade e nas obrigações comuns. Se o que se espera da família é a satisfação sexual dos cônjuges, isso pode ser conseguido de outras formas, sem necessariamente constituir uma família, tendo os filhos apenas como acidentes de percurso. ${ }^{81}$

\section{IMPLICAÇÕES DA DEMOCRATIZAÇÃO PARA A FAMÍLIA BRASILEIRA CONTEMPORÂNEA}

Mudanças tão significativas provocam tensões e até mesmo novos problemas jamais antes suscitados.

Há implicações para este novo tipo de família, inconsistências do próprio modelo. Sabese, que na prática, a igualdade entre homens e mulheres não corresponde à realidade das leis. Embora a CF/88 disponha serem todos iguais perante a lei, fazendo crer que homens e mulheres têm tratamento isonômico, ainda assim, a isonomia não pode ser levada às últimas consequências, porque existem evidentes diferenças biológicas, psicológicas e materiais entre o homem e a mulher. ${ }^{82}$ Portanto,

Determinadas desigualdades biológicas e materiais são legítimas, sendo defensável e compreensível preservar certos privilégios em favor das pessoas ainda havidas como vulneráveis como fez ver Aristóteles ao perceber ainda na era pré-cristã o equívoco de uma igualdade meramente formal, ao celebrizar o primado de que "a igualdade consiste em tratar igualmente os iguais e desigualmente os desiguais" $" 83$

Nem todas as mulheres, nem todos os homens têm as mesmas condições para usufruir da igualdade de direitos; seja pela discriminação salarial em relação às mulheres, seja também pela divisão desigual das tarefas domésticas e os cuidados com os filhos. ${ }^{84}$

O próprio IBGE registra a divisão dos afazeres domésticos como um dos aspectos em que ainda há um elevado grau de desigualdade entre homens e mulheres. No Brasil, a média de horas gastas pelas mulheres em afazeres domésticos é mais do que o dobro da média de horas

81 MENESES, Paulo. A família: uma abordagem filosófica. UNICAP, Pernambuco, 2013. Disponível em:<http://www.unicap.br/Pe_Paulo/documentos/a_familia.pdf>. Acesso em: 06 fev. 2013.

${ }^{82}$ MADALENO, 2011, p. 49.

83 Ibid., loc. cit.

${ }^{84}$ TORRES, A. C. Aumento do divórcio, mudanças na família e transformações sociais. In: CURSOS INTERNACIONAIS DE VERÃO DE CASCAIS. 5.,1999, Cascais.Portugal. Actas...,Cascais, 1999. p.77. 


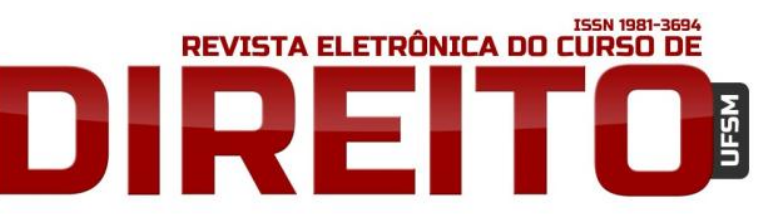

A DEMOCRATIZAÇÃO DA FAMÍLIA: SUBSTITUIÇÃO DA HIERARQUIA FAMILIAR PELA PARIDADE NAS RELAÇÕES CONJUGAIS E SUAS IMPLICAÇÕES PARA A FAMÍLIA BRASILEIRA CONTEMPORÂNEA

despendidas pelos homens. Em 2009, enquanto as mulheres ocupadas gastaram, em média, 22,0 horas semanais em afazeres domésticos, a média entre os homens foi de 9,5 horas. ${ }^{85}$

Tem sido largamente demonstrado que essas tarefas continuam a ser das mulheres, que apesar de trabalharem fora de casa, ainda assim devem se ocupar essencialmente dos afazeres domésticos.

A figura abaixo demonstra essa realidade no Brasil.

Figura 2 - Média de horas semanais gastas em afazeres domésticos, total e pessoas ocupadas, segundo o sexo - Brasil - 2009

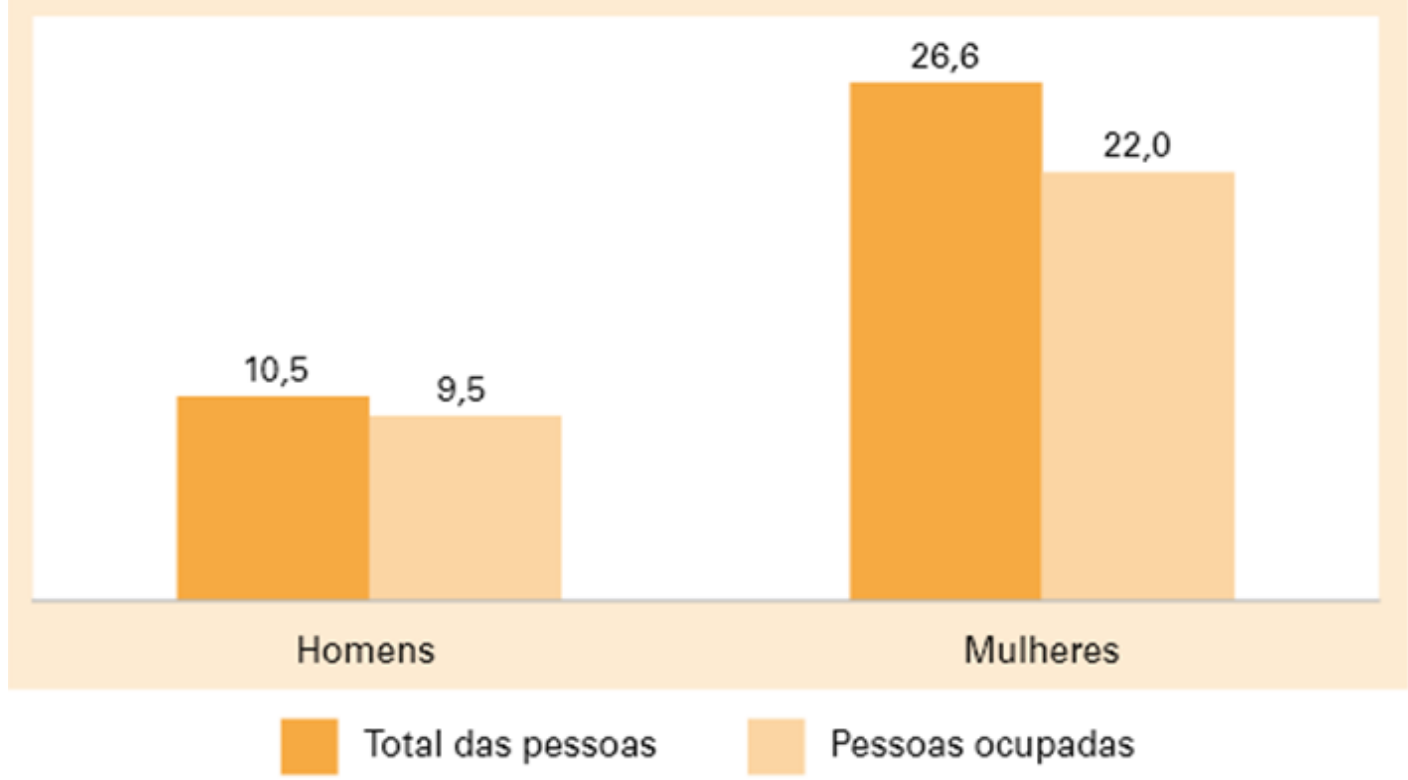

Fonte: IBGE, Pesquisa Nacional por Amostra de Domicílio (2009) apud IBGE (2013)

Apesar do aumento da taxa de atividade das mulheres, essas permanecem como as principais responsáveis pelas atividades domésticas e cuidados com os filhos e demais familiares, o que representa uma sobrecarga para aquelas que também realizam atividades econômicas.

A par de todas as exigências que recaem sobre a mulher profissional, continua também a the caber tudo o que diz respeito ao funcionamento da família.

Cobra-se das mulheres trabalhadoras do fracasso escolar das crianças à violência urbana. Volta a encontrar eco o discurso do início da industrialização de que as

\footnotetext{
${ }^{85}$ IBGE, 2013, p. 77
} 
mulheres roubam trabalho dos homens, rebaixam o salário de todos e deixam as famílias em total abandono. ${ }^{86}$

Esse discurso deixa transparecer que, apesar de se reconhecer legalmente a igualdade entre os cônjuges, permanece arraigada na sociedade contemporânea a ideologia de sociedade patriarcal, a convicção de que o espaço que cabe às mulheres é o privado, ou seja, o doméstico.

Para Pereira, "o grande grito da contemporaneidade é o da igualdade. Igualdade dos direitos entre homens e mulheres, das raças, dos estrangeiros, das classes sociais". ${ }^{87}$ No entanto, afirma:

A questão da igualização de direitos entre os gêneros não se resolveria simplesmente através de textos legislativos. No Brasil, por exemplo, a Lei Maior, mais que declarar, afirma essa igualdade. Entretanto, não há de pronto, ainda e de fato, tal igualdade. Há uma distância entre o fato e o direito. ${ }^{88}$

Os fatos geradores do apartheid feminino, embora, nos dias atuais, bem menos acentuado que no passado, estão na essência da própria cultura ${ }^{89}$. Em decorrência disso, os ordenamentos jurídicos são tradutores destas culturas. Portanto, “apesar da proclamação da igualdade pelos organismos internacionais e pelas Constituições democráticas [...], não está dissolvida a desigualdade de direitos dos gêneros." 90

Madaleno afirma que:

a faixa negra da arbitrariedade masculina, que externa o duvidoso gosto azedo da desigualdade entre cônjuges, não transita pela partilha democrática do encargo de direção da família, assegurado pela vigente Constituição Federal, mas desponta sim, na dura e triste constatação de existir, como já antes dito, um código invisível que açambarca boa parcela das relações afetivas entre o homem e a mulher - regendo uma resignada dependência, lamentavelmente ensinada à mulher ${ }^{91}$

\footnotetext{
${ }^{86}$ NOBRE, 2004, apud BERTOLIN, Patrícia Tuma Martins, CARVALHO, Suzete. A segregação ocupacional da mulher. In: BERTOLIN, Patrícia Tuma Martins, ANDREUCCI, Ana Cláudia Pompeu Torezan (Org.). Mulher sociedade e direitos humanos. São Paulo: Rideel, 2010. p. 204.

${ }^{87}$ PEREIRA, 1997. p. 101

${ }^{88}$ Ibid., loc. cit.

${ }^{89}$ lbid., p. 103.

90 Ibid., loc. cit.

91 MADALENO, Rolf. Direito de Família Constituição e Constatação. Rolf Madaleno, São Paulo, 2012. Disponível em <http://www.rolfmadaleno.com.br/rs/index.php?option= com content\&task =view\&id26\&Itemid=39. Acesso em: 24 ago. 2012
} 
A conclusão de Madaleno é que de nada serve projetar paridades, se à esposa ou companheira continuam faltando oportunidades no mercado de trabalho ${ }^{92}$

Verucci pergunta se o Direito estaria acompanhando a realidade social e seus novos valores e se os preconceitos tão enraizados principalmente acerca da discriminação e coisificação da mulher podem ser combatidos seriamente através da legislação. ${ }^{93}$

Atualmente "a família não é mais apenas o reflexo da imagem de uma comunidade. Transformou-se, de organismo biológico e econômico, em uma criatura social, humanizada."94 Edifica-se uma nova concepção de família, psiquicamente moldada pelos arquitetos da emoção, organizada juridicamente com feições democráticas, e de conteúdo moral desestigmatizado. ${ }^{95} \mathrm{~A}$ família não mais se estrutura na verticalidade, tampouco se subsume a uma relação genética e consanguínea. "Encontra-se atualmente alicerçada numa arquitetura horizontal, construída sobre os pilares da igualdade, do afeto e da solidariedade." 96

Por fim, a busca pela igualdade nas relações conjugais não é tarefa fácil e tão simples assim. Ela está entremeada de uma complexidade que o pensamento jurídico, por si só, não é capaz de responder. "Essa complexidade poderá começar a ser desvendada quando, com a ajuda de outras disciplinas ou ciências, começarmos a pensar a igualdade a partir das diferenças" "97

\section{CONCLUSÃO}

Além das considerações históricas sobre a formação da família brasileira, procurou-se abordar o fundamento que inspirou sua democratização, bem como os fatores que contribuíram para o afastamento da concepção hierárquica e matrimonial da família. Também se discutiram as implicações desse novo modelo de família, de forma a promover reflexões sobre o Direito das Famílias, uma vez que a família como instituição é capaz de modelar e remodelar sua estrutura

\footnotetext{
${ }^{92}$ MADALENO, 2012.

${ }^{93}$ VERUCCI, Florisa apud CHAVES. 1991, p. 318.

${ }^{94}$ SAAD, 2010, p. 31.

95 Ibid., loc. cit.

96 Ibid., p. 32.

97 PEREIRA, 1997, p. 108.
} 
a partir do contexto social, histórico e cultural em que está inserida. Como unidade orgânica, a família é, antes de tudo, um fenômeno sociológico antes de ser um fenômeno jurídico.

Não basta conhecer o conteúdo das leis. É importante avaliar as causas que motivaram as transformações na legislação do Direito das Famílias.

O operador do direito estará apto a compreender a razão, o motivo e a finalidade das leis, bem como saberá melhor interpretá-las e aplicá-las ao caso concreto.

Desse modo, o texto apresentou a democratização da família como decorrente de mudanças sociais e culturais que ocorreram nas últimas décadas, sobretudo em relação às concepções globais sobre o papel da mulher, as quais refletiram diretamente no campo do Direito das Famílias.

Não há dúvida de que o tema da igualdade dos sexos é um dos que se presta a maior número de confusões. Essa igualdade não pode ser confundida com a uniformidade total dos papéis do homem e da mulher, como o pretende, muitas vezes, um feminismo agressivo. É notório que a mulher vem alcançando, em quase toda a parte, uma igualdade de direitos com o homem. Porém, isto não quer dizer que se deva tornar semelhante a ele.

A mulher tem um papel a desempenhar não só dentro da família, mas também em toda a sociedade. Papel que é tão importante como o do homem; porém deve-se imprimir-lhe uma nota pessoal diferente.

Por fim, o artigo destacou os reflexos desse novo modelo de família, sob a justificativa de que toda mudança implica novas tensões e até mesmo novos problemas. Como ficou demonstrado, a igualdade formal existe, pois a lei tutela a igualdade entre os cônjuges. No entanto, na prática, a igualdade entre homens e mulheres não corresponde à realidade das leis.

A família caminha reescrevendo a sua história. O direito deve inserir-se neste processo com responsabilidade e atento às transformações da vida humana, seus conflitos e suas paixões.

\section{REFERÊNCIAS}

BERTOLIN, Patrícia Tuma Martins, CARVALHO, Suzete. A segregação ocupacional da mulher. In: BERTOLIN, Patrícia Tuma Martins, ANDREUCCI, Ana Cláudia Pompeu Torezan (Org.). Mulher sociedade e direitos humanos. São Paulo: Rideel, 2010.

BRASIL. Constituição (1988). Constituição da República Federativa do Brasil. Brasília, DF: Senado, 1988. 


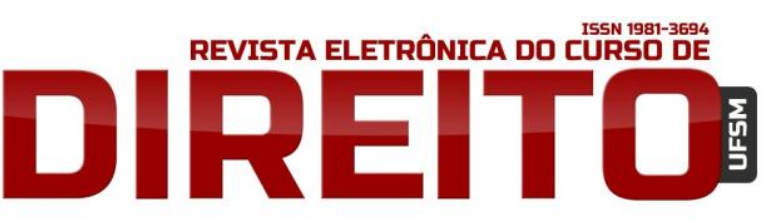

A DEMOCRATIZAÇÃO DA FAMÍLIA: SUBSTITUIÇÃO DA HIERARQUIA FAMILIAR PELA PARIDADE NAS RELAÇÕES CONJUGAIS E SUAS IMPLICAÇÕES PARA A FAMÍLIA BRASILEIRA CONTEMPORÂNEA

CASTELLS, Manuel. 0 poder da identidade. Trad.Klauss Brandini Gerhardt. 6. ed. São Paulo: Paz e Terra, 2008. v. 2.

CHAVES, Antônio. Direito de Família: Tratado de Direito Civil. 2 ed. São Paulo: Revista dos Tribunais, 1991. v.5.

COSTA, Claudia. Princípios constitucionais, igualdade e mulheres na Constituição de 1988. In: BERTOLIN, Patrícia Tuma Martins, ANDREUCCI, Ana Cláudia Pompeu Torezan (Org.). Mulher sociedade e direitos humanos. São Paulo: Rideel, 2010.

FREYRE, Gilberto. Casa grande \& senzala. Rio de Janeiro: José Olympio, 1933.

GOMES, Orlando. Direito de Família. Atualizador Humberto Theodoro Júnior. 11 ed. Rio de Janeiro: Forense, 1999.

HENRI-PAUL; LAUWE, Maria José Chombart de. A evolução contemporânea da família: estruturas, funções, necessidades. ICS.UL, Lisboa, 2013, Disponível em:

<analisesocial.ics.ul.pt/.../1224165225Z5aRR5fx5Sc98EV6.pdf>. Acesso em 06 fev. 2013.

IBGE: Síntese de Indicadores Sociais. Uma análise das condições de vida da população brasileira 2010. Estudos e Pesquisas, Informação Demográfica e Socioeconômica. IBGE, 2013 Disponível em:

http://www.ibge.gov.br/home/estatistica/populacao/condicaodevida/indicadoresminimos/sinte seindicsociais2010/SIS_2010.pdf. Acesso em: 07 mar. 2013.

LÔBO, Paulo. Direito Civil: Famílias. 4. ed. São Paulo: Saraiva, 2011.

MADALENO, Rolf. A desigualdade conjugal do código civil. Revista do Advogado: Família e Sucessões. São Paulo. Ano 31, n. 112, p. 151-161, jul. 2011.

Curso de direito de família. 4. ed. Rio de Janeiro: Forense, 2011.

. Direito de Família Constituição e Constatação. Rolf Madaleno, São Paulo, 2012.

Disponívelem <http://www.rolfmadaleno.com.br/rs/index.php?option=

com_content\&task=view\&id=26\&ltemid=39. Acesso em: 24 ago. 2012

MENESES, Paulo. A família: uma abordagem filosófica. UNICAP, Pernambuco, 2013. Disponível em:<http://www.unicap.br/Pe_Paulo/documentos/a_familia.pdf>. Acesso em: 06 fev. 2013.

PONTES DE MIRANDA, J.C. Tratado de direito de família. Atualizador Vilson Rodrigues Alves, Campinas: Bookseller, 2001, 2v.

MONCORVO, Maria Cecília Ribeiro. Criando os filhos sozinha: a perspectiva feminina da família monoparental. 2008. 106 f. Dissertação (Pós-Graduação em Psicologia) - Pontifícia Universidade Católica do Rio de Janeiro. 


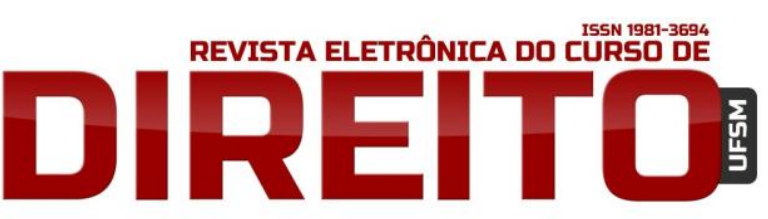

A DEMOCRATIZAÇÃO DA FAMÍLIA: SUBSTITUIÇÃO DA HIERARQUIA FAMILIAR PELA PARIDADE NAS RELAÇÕES CONJUGAIS E SUAS IMPLICAÇÕES PARA A FAMÍLIA BRASILEIRA CONTEMPORÂNEA

MOVIMENTO feminista. Brasil.gov, Brasília, 2013. Disponível em:

<http://www.brasil.gov.br/secoes/mulher/atuacao-feminina/feminismo-pela-igualdade-dosdireitos>. Acesso em: 06 mar. 2013.

PEARCEY, Nancy. Como as mulheres começaram a guerra cultural. In: . Verdade absoluta. Rio de Janeiro: CPAD, 2006. Cap. 12, p. 363-390.

PEREIRA, Rodrigo da Cunha. Direito de Família: uma abordagem psicanalítica. Belo Horizonte: Del Rey, 1997.

. Princípios fundamentais e norteadores para a organização jurídica da família. 2004. 157 f. Tese (Doutorado em Ciências Jurídicas) - Universidade Federal do Paraná, Curitiba.

PICKINA, Eugênia M. V. Araújo. O público e o privado. In: BERTOLIN, Patrícia Tuma Martins, ANDREUCCI, Ana Cláudia Pompeu Torezan (Org.). Mulher sociedade e direitos humanos. São Paulo: Rideel, 2010.

SAAD, Martha Solange Scherer.A evolução jurídica da mulher na família. In: BERTOLIN, Patrícia Tuma Martins, ANDREUCCI, Ana Cláudia Pompeu Torezan (Org.). Mulher sociedade e direitos humanos. São Paulo: Rideel, 2010.

SAMARA, Eni de Mesquita. O que mudou na família brasileira? (da colônia à atualidade). Psicologia USP. São Paulo, v 13, n 2, 2002.

SHERE, Hite. Contra os favores do homem: a visão de uma feminista que procura destruir mitos sobre a vida sexual da mulher. Veja,São Paulo, 1978. Seção Páginas Amarelas. Disponível em: <http://veja.abril.com.br/acervodigital/home.aspx>>. Acesso em 18 set. 2012.

TORRES, A. C. Aumento do divórcio, mudanças na família e transformações sociais. In: CURSOS INTERNACIONAIS DE VERÃO DE CASCAIS. 5.,1999, Cascais.Portugal. Actas...,Cascais, 1999.

VENOSA, Silvio de Salvo. Direito Civil: Direito de Família. 5 ed. São Paulo: Atlas, 2005, v.6

Recebido em: 30.09 .2013

Correções em: 04.12.2013

Aprovado em: 29.12.2013 